\title{
Reinhart Koselleck, Sediments of Time: On Possible Histories, translated and edited by Sean Franzel and Stefan-Ludwig Hoffman. Stanford University Press. 2019. xxxi +301 pages. ISBN 9781503605978
}

\author{
Timo Pankakoski \\ University of Helsinki, FI \\ timo.pankakoski@helsinki.fi
}

Keywords: Reinhart Koselleck; conceptual history; philosophy of history; temporality; metaphor

This recent translation offers Reinhart Koselleck's work in its most essayistic and speculative, but perhaps, also the most inspiring forms. Extrapolations, parallels, and analogies suggest themselves on nearly every page of this intriguing volume. In terms of implications and side steps, the content ranges from climate change and melting ice caps to railways and the experienced acceleration of time, and all the way to war memorials and the layered tranquility of cemeteries and mass graves.

Primarily, however, the book offers a heavy dose of Koselleck's Historik, or the theory of possible history. Or perhaps, to exploit Jacob Taubes's characterization of Koselleck as a "partisan for histories in the plural," cited by Niklas Olsen and others, we should characterize Koselleck as a partisan for possible histories. While this perspective arguably underlies in rudimentary forms, a large part of his work in general, here Koselleck expressly tackles some of the most fundamental questions in historical theory, including the following: How is history possible in the first place? How, exactly, are historical experiences conditioned by anthropology? How do individuals' historical experiences turn into supra-human history or history as such? How can we combine the observations of history as both movement and repetition into a single coherent image? How should we understand the causal and temporal relations between historical events and their linguistic (re-)descriptions? How is historical time related to geographical or geopolitical space? And so forth. The volume thus further elaborates several elements that support Koselleck's analyses in conceptual history and his political thinking, and it can be expected to be of interest to a wide audience in history, philosophy, political studies, cultural studies, and the social and human sciences more broadly.

Sediments of Time is a representative selection - representative in the sense that it consists of texts from the 1980s and 1990s, published in Koselleck's three late collections in German. With seven essays from Zeitschichten ,'Temporal Layers,' (2000), two from Begriffsgeschichten, 'Histories of Concepts,' (2006), and six from Vom Sinn und Unsinn der Geschichte, 'On the 
Meaning and Absurdity of History,' (2010), accompanied by one further interview, the present edition is a collection based on collections, or a selection from selections. Hopefully this does not imply that the original collections will not be translated in their entirety. This would be unfortunate not only as regards systematicity, but also because the essays left out of the present translation offer several useful perspectives. Some of them, however, are available in the volume The Practice of Conceptual History: Timing History, Spacing Concepts, equally published in the series 'Cultural Memory in the Present' by Stanford University Press in 2002. The otherwise insightful introduction could have elaborated on why particularly these texts were selected and which aspects still remain in shade.

Many of the essays in Sediments of Time are precisely what the term 'essay' originally conveyed - attempts to clarify complex phenomena; thinking here and now and from a certain viewpoint, often based upon perhaps representative but chosen historical examples amongst a host of others that could have produced dissimilar impressions. It is not by coincidence that Montaigne's Essais, as the editors' introduction tells us, was the third book Koselleck would have taken with him to a deserted island alongside the Bible and Jacob Burckhardt's Weltgeschichtliche Betrachtungen. The most essayistic passages carry an implicit "it seems to me" or "here and now" perspective, even though the author, who has in the meanwhile become an internationally recognized classic, is liable to be read as having pursued more categorical forms of knowledge, too.

Koselleck's writing is consistently molded by characteristically German perspectives, not only in terms of the actual or hypothetical audiences or the historical sources and key concepts he analyzes but also as regards the historical experiences he theorizes, notably including those of ideological intensification, terror, guilt, mourning, ambivalent memorizing, and eventual national unification. In contradistinction to the almost formalized and effectively globalized methods of conceptual history and the equally generalized historical hypothesis of the saddle time (the applications of which are nowadays mushrooming worldwide), the above-mentioned reflections on historical experiences are perhaps the aspect of Koselleck's work to be the least capable of traveling outside the original Central European confines.

Simultaneously, however, the collection is characterized by the attempt to sketch the widest and most formal preconditions of human history in a purportedly universal key and with terminology ironically reminiscent of that of transcendental philosophy. The price for this ambitious claim for validity is paid for by the abstractness of Koselleck's key anthropological categories, which often also invites metaphorical usages and connotations. The oppositional pairs of above/below, inside/outside, and before/after, are broad enough to cover not only all historical experience, but all experiences of the world in general, as observing things in space and time is an inalienable aspect of human cognition and perception. The metaphorical extensions of "above/below" to connote power relations or "inside/outside" to imply social belonging or exclusion, by contrast, are already significantly more culturally preconditioned implications of the minimal anthropological framework. In occasionally bringing these tones to the discussion, Koselleck subtly extrapolates from the categories of universal political anthropology to more particularistic critical analysis of history and ideology.

Equally, although conflict in some abstract form is easy to accept as a perpetual element of the human condition, one may wonder whether the friend/enemy principle is a sufficiently formalized framing of the conflict principle to warrant the conclusion that all history is experienced in exactly these categories. The formulation rather seems to inject the supposedly timeless anthropological basis with elements drawing from mid-European 20th-century historical experience and Koselleck's personal life history. As the editors correctly note, "Koselleck never made a secret of the influence of [Carl] Schmitt's conceptual rigor (but not his politics) on his writings" (p. XXI). The way Schmittian modes of thought molded Koselleck's 
way of asking questions and his concomitant repertoire of possible answers, particularly in his formative years, is still a topic of ongoing debate. Making more sources directly available to Anglophone readers is a worthy contribution also from this perspective, as it enables direct access to how Koselleck utilized Schmittian parlance still in his late texts, yet also reworked the perspective. Particularly the essays 'Behind the Deadly Line' (1999) and 'Concepts of the Enemy' (1993), respectively, are relevant for these two intertwined aspects. A slightly more nuanced and contextualizing introduction might have been helpful in situating all the essays into Koselleck's intellectual development and into German intellectual history more broadly.

Koselleck's thinking both exemplifies and consciously theorizes the problematic relationship between steadily recurring and context-bound elements in historiography. Rejecting capitalized History as a single supra-human phenomenon, on the one hand, and the complete incommensurability of historical experiences because of their ultimate singularity, on the other, he opts for a supposed third way. History consists of singular events, but the series they form in historiographical analysis reveals recurring features and repetitive structures. Koselleck's theory reaches beyond the Enlightenment idea of history as inevitable single and linear progress, but equally abhors the Nietzschean eternal return of the same. Historical events experienced in the present moment take place upon the basis laid by earlier epochs, are preconditioned by recurring historical structures, are made sense of in the light of previous historical experiences, and are often described in highly conventional vocabulary - yet they are still distinct and take history forward, as in a spiral. And vice versa, although events may be unique, they rely on previous stratified experiences.

The geological metaphor of sedimentation in the title of the volume is instrumental for Koselleck's attempt to sail between the extremes of full-blown relativistic historicism and a single universal world history. The rapid and apparently singular, perhaps even meaningless, everyday events of surface history, after all, take place upon a fundament into which earlier historical happening has gradually solidified. Slow historical processes thus precondition quicker ones, and the past is present in the contemporary moment through what Koselleck and other German thinkers called 'the contemporaneousness of the non-contemporaneous.'

Technically, 'layers' or 'strata' would perhaps have been a more accurate translation for Schichten. The German language has the corresponding word for 'sediment,' and had Koselleck wanted to express what that word conveyed and connoted, he could have done so. In some passages, the translators protect the nuances by including both terms, as exemplified by the cases of "sediments or layers of time" (Zeitschichten) or the slightly redundant 'sedimented layering' (Abschichtungen). In the introduction, the editors explain that they chose to translate Zeitschichten as sediments (rather than layers) of time in order to better capture the aspect of these layers being either formed or eroded with different velocities. This is indeed pivotal to keep in mind while studying Koselleck's theory of history, but whether this point should necessarily be codified into the very concept of temporal layers is another matter.

The downside is that when confronted with further variants of the same motive, the translators must in any case resort to 'layers' rather than 'sediments,' such as in rendering Koselleck's mehrschichtige Zeittheorie as 'multilayered theory of time,' because the word 'multi-sedimented' would be particularly unpleasant to the eye. With the noun and its derivatives thus translated differently, the subtle metatheoretical structure of Koselleck's writing becomes disintegrated. This is difficult, if not impossible, to avoid completely in any translation, and scholars working on the textual level of Koselleck's thought probably use original editions anyway.

Nevertheless, these translation decisions affect the lay reader alike because they have a bearing on how we understand the key points of Koselleck's theory of history. First, sediments form upon the surface of the planet or at any rate closer to it than layers, which rather 
connote depth and hiddenness, and, by metaphorical extension, profundity. The translation of Schichten as sediments thus intuitively makes us think of the more rapidly changing upper layers of the historical-social structure, and the underlying (no pun intended) conservative tones in Koselleck's thought are thereby somewhat relativized.

Second, it seems that the chosen terms of sediments and sedimentation emphasize process and change more emphatically than layers. We intuitively understand geological layers as stable and unchanging within any time frame observable by human beings apart from occasional and very rare volcanic convulsions. Sedimentation, by contrast, is something that happens on a daily basis, as the same process can be observed in forests or bottoms of lakes within a time frame of years, if not months. While time layers emphasize gradual or rare change in primary stability, sediments underscore the process dimension and the aspect of how stable layers originally come into being. The translators also subtly put forth this interpretation for instance by translating Koselleck's 'theory of temporal layers' (Zeitschichtentheorie) in one passage as 'a theory of sedimentation,' wherein already the -ion ending emphasized the process dimension somewhat more forcefully than the original. The more dynamic nature and the lesser time scale of 'sedimentation' as opposed to 'stratification' seems to be contained, through its differing connotation, within the very concept - a welcome reminder of Koselleck's theory of time layers within concepts, ironically mapped upon his own text in a slightly inaccurate translation.

Given Koselleck's habit of playing with words, any attempt to translate in terms of both comprehensible meanings and accurate terminology are, of course, doomed to fail at the outset. For instance, Zeitgeschichte can be understood both as contemporary history and the history of time, wherein the very word of history already carries an etymological hint toward layers, and in one of the essays Koselleck elaborates all these aspects in the categories of constancy and change of contemporary history. The editors wisely left the term Zeitgeschichte untranslated here, and the same goes for Koselleck's central term of Historik.

Many of the texts have originally emerged as plenary lectures or speeches in special occasions and still carry traces of the spoken word. In one such text, Koselleck lauds Goethe's untimeliness, or his ability to resist the fashionable tendency of the era to interpret history in terms of the philosophy of history as a unilinear and goal-oriented process. The essay thus supplements Koselleck's discussion on the collective singular of history in Futures Past and elsewhere. However, it also carries links to the theorizing of temporal layers elsewhere in the present volume, for Koselleck identifies in Goethe a sustained attempt to read history as sedimented and repetitive in a quasi-geological framework and expressly suggests this as a counter-image to history as linear development. To what extent this, however, is a methodological-linguistic projection from Koselleck's own perspective rather than a pure historical finding, remains unclear in the text due to the lack of explicit references, as determined by the genre of ceremonial speech. The same goes for the way Koselleck "finds" - as he put this in a later interview, equally published in the volume - his own metahistorical conceptual pairs of inside/outside, above/below, and earlier/later incessantly recurring in Goethe's thought. Given the high level of generality of these categories, the contrary finding would be genuinely surprising.

Another noteworthy study in applied sedimentation theory focuses on modern warfare and links the question of time layers to how modern wars are anticipated, experienced, and memorized. The two global wars of the 20th century obviously had an effect on anyone alive at the time, and many of these experiences were similar regardless of whether the subject belonged to the victors or the vanquished. Sometimes, however, also the long-passed were effected, as exemplified by Goebbels's 1935 demand that the names of Jewish WW1 veterans be effaced from war memorials - not to mention the numerous ways in which the past war 
for a long time preconditioned the life of those born after 1945. Oscillating between several of Koselleck's key interests, the essay highlights connections between Koselleck's theory of historical layers, his reflections on memory and mourning and the visual representations of wars, and the abstract conditions of all possible history or Historik - particularly through the theme of mortality and the ability to kill as anthropological constants allegedly molding any experience of history.

Koselleck's tendency to return to his darlings, often bordering on, or amounting to, verbatim recycling of earlier passages, becomes a virtue here, as it not only helps the beginner to get an overall view of Koselleck's long-time interests with relatively little effort but also provides the advanced scholar with material for comprehensive estimations on the links between the various elements in his nuanced historical thinking. The same goes for the volume in its entirety. The essays compiled here paint a colorful image of a certain Koselleck - the theorist of historical experience, the anthropological speculator, the partisan of possible histories, and the essayist and champion of the feuilleton - and in so doing usefully supplement the other Kosellecks focusing, inter alia, on histories of individual concepts, social history, criticism of ideology, or Enlightenment historiography, respectively. The admirable manifoldness of Koselleck's intellectual efforts, despite occasional repetitiveness and shortcomings, is yet another reason to make his work extensively available to Anglophone readers who will find a lot to chew on in this stimulating sample.

\title{
Competing Interests
}

The author has no competing interests to declare.

\begin{abstract}
How to cite this article: Pankakoski, Timo. 2019. "Reinhart Koselleck, Sediments of Time: On Possible Histories, translated and edited by Sean Franzel and Stefan-Ludwig Hoffman. Stanford University Press. 2019. xxxi + 301 pages. ISBN 9781503605978." Redescriptions: Political Thought, Conceptual History and Feminist Theory 22(1): 83-87. DOl: https://doi.org/10.33134/rds.308
\end{abstract}

\section{Submitted: 15 October 2019 Accepted: 15 October 2019 Published: 03 December 2019}

Copyright: (c) 2019 The Author(s). This is an open-access article distributed under the terms of the Creative Commons Attribution 4.0 International License (CC-BY 4.0), which permits unrestricted use, distribution, and reproduction in any medium, provided the original author and source are credited. See http://creativecommons.org/licenses/by/4.0/.

\section{HUP P}

